\title{
Uses of Yoga and Physiotherapy in Depression
}

\author{
Lipika Buragohain, Nilofar Yasmin and Chandana Choudhury Barua* \\ Department of Pharmacology and Toxicology, College of Veterinary Science, Assam Agricultural University, India
}

Submission: June 05, 2018; Published: June 19, 2018

*Corresponding author: Chandana Choudhury Barua, Professor and Principal Investigator, Department of Pharmacology and Toxicology, College of Veterinary Science, Assam Agricultural University, Guwahati, Assam-781022, India, Tel: (+91) 9864013231;

Email: chanacin@gmail.com

\begin{abstract}
The practices of yoga and physiotherapy for people suffering from depression relaxes mind and muscles which improves muscle strength, flexibility, blood circulation and oxygen uptake as well as hormone function. The state of the mind and that of the body are intimately related. If the mind is relaxed, the muscles in the body will also be relaxed. These will also reduce a variety of important risk factors for various diseases, especially cardio-respiratory diseases. Changing the stress mindset not only minimizes the effects of stress, it enhances performance and productivity.
\end{abstract}

Keywords: Yoga; Physiotherapy; Depression; Stress

\section{Introduction}

We are living in a world overwhelmed with stress. The intolerant pace and complexity of our daily life has greatly challenged our ability to live healthily and fully in the present moment. Stress is present in each one of our lives to varying degrees. Stress refers to two things the physiological perception of pressure and how our body responds to it which involves multiple systems, from metabolism to muscles to memory. Any stressful event triggers a cascade of hormones, adrenaline and cortisol that rush through the body indirectly speeding up our heartbeat and circulation of blood which mobilize fat and sugar for fast energy, prepare muscles for action, focusing attention. Over the last few decades, stress is an alarming and rising issue among the people. From meditation to yoga to arduous activity to therapeutic drugs used by the people to fight for stress and anxiety yet it lacks in getting fully relief from it in this demanding world.

There are different types of stress with its own symptoms and characteristics, acute stress is commonly found. Acute stress disorder is the progenitor of chronic post shock stress disorder. It is the common stress found among people which comes from pressure of work, emotional distress etc. It comes on quickly and often unexpectedly and does not last too long. Body stress response is triggered with acute stress but it can be reverse with quick relaxation techniques. Various stress relievers can help to relax and recover acute stress. This includes breathing exercise, progressive muscle relaxation, mini-meditation etc. [1].

Another type of stress is the chronic stress. It is the type of stress that tends to occur on the regular basis which destroys bodies, minds and lives. It wreaks havoc through long-term attrition. When the stress response is chronically triggered and the body is not brought back to the relaxed state before the next wave of stress hits, the body can stay triggered indefinitely. This led to numerous health issues that are generally associated with stress, including cardiovascular disease, gastrointestinal issues, anxiety and depression. This is why it is important to manage chronic stress effectively. Long term habits like regular exercise, regular meditation than help better to manage chronic stress [1].

Emotional Stress is another type of stress which can hit harder than some other types of stress. For example, the stress that comes from a conflicted relationship tends to bring a greater physical reaction and a stronger sense of distress than the stress that comes from being busy at work. There are many efficient ways to cope up with the emotional stress. Strategies that help to process, diffuse, and build resilience toward emotional stress can all work well, and different approaches can work in different situations. Consulting a physiotherapist is the main remedy for emotional stress [1].

The conceptual background of yoga has its origins in ancient Indian philosophy. In India, however, Yoga is considered more than a physical exercise, it has both meditative and spiritual core by which one can control their body and mind. The application of yoga as a therapeutic intervention, which began early in the twentieth century, takes advantage of the various psychophysiological benefits of the component practices [2]. Depression and anxiety are treated by different types of meditation and other stress-reduction techniques. Since the 1980s, yoga is popular as a system of physical exercise in the 
western world as well. In U.S. 7.5\% adults tried yoga at least once, which was estimated by a national survey and yearly it is increasing [3]. More studies are using randomized controlled trials to look at the relationship between yoga and depression. In India, a majority of the research were done on yoga as a therapeutic intervention which were published in Indian journals and day by day people are gaining this knowledge of yoga which they were unaware [4]. Numerous studies have shown yoga to have an immediate down-regulating effect on both the HPA axis responses to stress. Effectiveness of yoga against stress management is well established [5]. According to the Harvard Mental Health Letter, recent studies suggest that practicing yoga can reduce the impact of stress, help with anxiety and depression, be a self-soothing technique similar to meditation, relaxation, and exercise and improve energy [6]. Yoga is a complementary treatment of depression [7].

As exercise, yoga is a natural way to increase serotonin production. According to the Journal of Psychiatry and Neuroscience, serotonin production plays a role in the treatment of depression [8]. Serotonin is also called as happy chemical as it contributes happiness. Depressed people have lower levels of serotonin. Yoga is also especially helpful because of its gentle, calming, and fluid nature which encourages to focus on positive images to calm the body and mind.

Famous yoga Guru, B. K. Iyengar said "Yoga does not change the way we see things, it transforms the person who sees it". Infact, June $21^{\text {st }}$ is celebrated as International Yoga day and in India it has gained momentum due to patronage of Prime Minister Narendra Modi, who is an ardent follower of Yoga and this might be his secret of keeping good health and stamina and bountiful energy. This year's theme for Internationals yoga day is "Yoga for health".

Everyone is aware of the physical benefits of physical therapy as it is utilized for the supplementary treatment of various physical ailments, but the role of physiotherapy in mental health is lesser known. Physical therapy and exercise treatment for depression have direct benefits as it stimulates the body's own nervous system and acts as therapy to reduce stress. The role of physiotherapy in mental health is to stimulate the release of endorphins from the pituitary gland. Endorphins are the hormones that improve the mood and relieve stress. Physical therapy also helps in suppressing the hormone Cortisol which is found to be elevated in depression patients [9].

For those who are reluctant to take anti-depressants, exercise treatment is the best choice. Exercise releases endorphins which is a natural anti-depressant. Physical therapy has no side effects and improvement in mood can be observed after just one session. However, these effects are short-term and regular physical exercise is required to show prolonged results. Physical therapy for depression can show various benefits and help fight the symptoms of depression without the use of harmful anti-depressants. A guided self-help programme from a trained practitioner may work for depression. It takes time, motivation and effort to get relief by constantly monitoring the progress [9].

Physiotherapy for stress, directly doesn't involve physical exercises, therapies etc. but a well design perfect care plan that includes effective exercises to powerful therapy sessions to meet the requirements which vary individually. In yoga, breathing exercises, physical exercises, muscle strength, relaxation therapy, massage of body are the different forms generally the physiotherapists suggests for stress, anxiety and mental disorder [10]. There are several popular approaches to manage or reduce stress which includes enhancing cognitive awareness of stressors and coping [11]. Various relaxation techniques such as biofeedback, autogenic training, visual imagery, self-hypnosis [12]. Improving interpersonal communication by techniques such as assertiveness and understanding behavioral style but not many studies are done to get the relative efficacy of these techniques. One of the technique with which research is done and found effective is yoga and meditation. Stress management programs based on cognitive behavioural therapy and kundalini yoga program, the study reveals that both cognitive therapy and yoga are promising stress management techniques used today [13]. In the modern context, yoga may be defined as a systematic practice and accomplishment of our mind and body in the living body to keep harmony within self, society and nature $[14,15]$.

\section{Conclusion}

Yoga cannot be called as a physical exercise or a system of therapy rather it is a science and art of holistic healing by which we experience a peaceful mind and feel better. Relaxation techniques, deep breathing, muscle flexibility exercises and arogonomics which improve the overall health and well-being of the patient. From age old time yoga always play a positive role in physical and mental health to lead a normal life.

\section{Conflict of Interest}

The authors declare that there are no conflicts of interest involved in this study.

\section{References}

1. Scott E (2018) Types of stress and stress relief techniques for each. Stress management.

2. Bussing A, Michalsen A, Khalsa SBS, Telles S, Sherman KJ (2012) Effects of yoga on mental and physical health: A short summary of reviews. Evid Based Complement Alternat Med, p. 7.

3. Yoga for anxiety and depression.

4. Khalsa SBS (2004) Yoga as a therapeutic intervention: a bibliometric analysis of published research studies. Indian J Physiol Pharmacol 48(3): 269-285.

5. Kirkwood G, Rampes H, Tuffrey V, Richardson J, Pilkington K, et al. (2005) Yoga for anxiety: A systematic review of the research evidence. Br J Sports Med 39(12): 884-891. 
6. Krans B (2016) Using Yoga to relieve the symptoms of depression.

7. Shapiro D, Cook IA, Davydov DM, Ottaviani C, Leuchter AF, et al. (2007) Yoga as a complementary treatment of depression: Effects of Traits and Moods on treatment outcome. Evid Based Complement Alternat Med 4(4): 493-502.

8. Young SN (2007) How to increase serotonin in the human brain without drugs. J Psychiatry Neurosci 32(6): 394-399.

9. Physical Therapy for Depression -Edmonton \& Calgary Physio \& Massage Therapy | Physical Therapy.

10. Prasad 0 (2004) Role of yoga in stress management. West Indian Med J 53(3): 191-194.
11. Granath J, Ingvarsson S, Thiele UV, Lundberg U (2006) Stress Management: A randomized study of cognitive behavioural therapy and yoga. Cogn Behav Ther 35(1): 3-10.

12. Lazarus RS, Folkman S (1984) Stress, appraisal and coping. McGrawHill, New York, NY, USA.

13. Romas JA, Sharma M (2014) Practical stress management. A Comprehensive Workbook. ( $6^{\text {th }}$ edn), Pearson San Francisco, CA, USA.

14. Maharishi YV (1992) Journey of consciousness. Macmillan India, New Delhi, India, pp. 2-50.

15. Maharishi YV (1998) Logical solutions for the problems of humanity. Vethathiri Publications, Erode, India, p. 4

\section{Your next submission with Juniper Publishers} will reach you the below assets

- Quality Editorial service

- Swift Peer Review

- Reprints availability

- E-prints Service

- Manuscript Podcast for convenient understanding

- Global attainment for your research

- Manuscript accessibility in different formats

( Pdf, E-pub, Full Text, Audio)

- Unceasing customer service

Track the below URL for one-step submission https://juniperpublishers.com/online-submission.php 